\title{
Hidden Blood Loss in Adolescent Idiopathic Scoliosis Patients Undergoing Posterior Spinal Fusion Surgery: A Retrospective Study of 765 Cases in a Single Center
}

Lipeng Wang (D 18904807759@163.com )

Yijishan Hospital of Wannan Medical College

Jiangli Liu

Yijishan Hospital of Wannan Medical College

Xiaoxiao Song

Taikang Xianlin Drum Hospital, Medical school of Nanjing University

Muhui Luo

First Affiliated Hospital of Nanchang University

Yongquan Chen

Yijishan Hospital of Wannan Medical College

\section{Research Article}

Keywords: Hidden blood loss (HBL), adolescent idiopathic scoliosis, risk factors, multivariate linear regression analysis, posterior spinal fusion surgery, postoperative blood transfusion

Posted Date: June 4th, 2021

DOI: https://doi.org/10.21203/rs.3.rs-523705/v1

License: (c) (i) This work is licensed under a Creative Commons Attribution 4.0 International License.

Read Full License 


\section{Abstract}

Purpose: To investigate Hidden blood loss (HBL) and its potential risk factors in adolescent idiopathic scoliosis patients undergoing posterior spinal fusion surgery and elucidate the influence of $\mathrm{HBL}$ on postoperative blood transfusion.

Methods: We retrospectively studied 765 patients undergoing posterior spine fusion for adolescent idiopathic scoliosis from January 2014 to December 2018. The patient's demographics, blood loss related parameters, operation and blood loss information were extracted. The association between patient's characteristics and HBL was analyzed by Pearson or Spearman correlation analysis.

Multivariate linear regression analysis was used to determine independent risk factors associated with $\mathrm{HBL}$. Binary logistic regression analysis was used to analyze the influence of HBL on postoperative blood transfusion.

Results: A total of 765 patients including 128 males and 637 females (age range 10-18 years) were included in this study. The mean amount of HBL was $693.5 \pm 473.4 \mathrm{ml}$, accounting for $53.9 \%$ of the total blood loss. In multivariate linear regression analysis, we found that preoperative $\operatorname{Hct}(p=0.003)$ and allogeneic blood transfusion $(p<0.0001)$ were independent risk factors for $\mathrm{HBL}$, while tranexamic acid $(p=0.003)$ was negatively related to HBL. Binary logistic regression analysis showed that $\mathrm{HBL}>850 \mathrm{ml}$ ( $\mathrm{P}<0.001$, OR: $8.845,95 \% \mathrm{Cl}: 5.806-13.290$ ) was the independent risk factor for postoperative blood transfusion.

Conclusion: a large amount of HBL was incurred in adolescent idiopathic scoliosis patients undergoing posterior spinal fusion surgeries. Allogeneic blood transfusion and preoperative Hct were independent risk factors for $\mathrm{HBL}$, while tranexamic acid was negatively related to HBL. HBL and its influential factors should be taken into account when considering the perioperative transfusion management. These patients with HBL greater than $850 \mathrm{ml}$ should be paid more attention in case of postoperative anemia.

\section{Level of evidence: Level III}

\section{Background}

Blood loss remain a major focus in orthopedic surgery for adolescent idiopathic scoliosis due to extensive and complex operating procedure. Anesthesiologists and surgeons might mainly consider the visible blood loss including postoperative drainage, and ignore component penetration into the tissues, residual blood into vertebral canal and loss due to hemolysis, which was known to hidden blood loss [1]. The concept of HBL was firstly put forward by sehat in 2000 [2] and has received more and more attention by clinicians in recent years. Xu et al. [3] showed that the HBL in posterior lumbar interbody fusion surgery approximately accounted for $61 \%$ of total blood loss in rheumatoid arthritis patients. Kai et al. [4] also reported the HBL reached $1084 \mathrm{ml}$, accounting for $82 \%$ of total blood loss after hip hemiarthroplasty. HBL could deteriorate postoperative hemoglobin drop, resulting in increased blood transfusion requirement. Clarifying HBL will be of great importance for anesthesiologists to determine the 
strategies of perioperative blood transfusion. However, until now few published literatures have examined the hidden blood loss in posterior spinal fusion surgeries for adolescent idiopathic scoliosis. In this study, we retrospectively explored the amount of $\mathrm{HBL}$ in adolescent idiopathic scoliosis surgery and analyzed the influential factors of HBL.

The previous study reported that $23.4 \%$ patients required postoperative transfusion in posterior spinal fusion surgeries for adolescent idiopathic scoliosis [5]. Furthermore, we also found that a considerable number of patients still encountered anemia after the operation at our medical center, which requiring transfusion. Postoperative anemia will have a negative effect on the illness recovery and extended length of stay. This phenomenon may be associated with hidden blood loss. Therefore, clarifying the relationship between hidden blood loss and postoperative transfusion will be available to guide perioperative blood transfusion.

\section{Materials And Methods}

\section{Patients}

Institutional review board approval was waived as patients' private information was not retrieved. We retrospectively reviewed the medical date of 765 patients undergoing posterior spinal fusion surgeries for adolescent idiopathic scoliosis from January 2014 to December 2018 in our hospital. All the surgeries were performed by highly experienced surgeons using a uniform approach. Inclusion criteria were patients (1) younger than 18 years and diagnosed adolescent idiopathic scoliosis; (2) underwent posterior spinal fusion surgery; (3) obtained stable perioperative fluid balance and hemodynamics. Exclusion criteria were patients (1) with coagulation disorders or perioperative infection; (2) with anticoagulant drugs; (3) with intraoperative blood loss greater than $2.5 \mathrm{~L}$ on account to larger bias with excessive blood loss[6]; (4) suffered cerebrospinal fluid leakage.

\section{Date Extraction}

Demographic information were collected from electronic medical record including age, sex, height, weight, body mass index (BMI), preoperative and postoperative hematocrit (Hct) and hemoglobin ( $\mathrm{Hb})$, American Society of Anesthesiologists (ASA) classification, preoperative Cobb angle, prothrombin time and activated partial thromboplatin time; Surgery information included operation time, pedicle screw number, bone mineral density, the number of surgical segments, whether undergoing osteotomy, the use of tranexamic acid, intraoperative blood loss, postoperative drainage volume, and allogeneic and autologous blood transfusion volume.

\section{Blood Loss Management and Calculation of HBL}

Intraoperative blood loss was recorded by the anesthesiologist, which was mainly comprised of the blood in the suction apparatus and in the soaked gauzes that were used during the entire operation. Postoperative blood loss was calculated though measuring the blood volume in the hemovac. Most of 
the hemovac was removed on the third postoperative day, if the drainage tube can not be removed when calculating the blood loss, we measured the blood in the drainage tube on the day when the blood was taken. The total visible blood loss was calculated as the sum of intraoperative blood loss and postoperative drainage. The blood loss during the operative procedure could be collected by blood salvage technique and reinfusion to the patient as autologous blood, which was decided by the anesthesiologist. Patients were given blood transfusion when hemoglobin level was below $70 \mathrm{~g} / \mathrm{dL}$, or below $80 \mathrm{~g} / \mathrm{dL}$ with a significant symptom of anemia, such as increased heart rate hypotension. We calculated the patients blood volume (PBV) according to the formula described by Nadler et al. [7] PBV $(\mathrm{L})=\mathrm{k} 1 \times$ height $(\mathrm{m})^{3}+\mathrm{k} 2 \times$ weight $(\mathrm{kg})+\mathrm{k} 3,(\mathrm{k} 1=0.3669, \mathrm{k} 2=0.03219, \mathrm{k} 3=0.6041$ for male, and $\mathrm{k} 1=$ $0.3561, \mathrm{k} 2=0.03308, \mathrm{k} 3=0.1833$ for female). The total red cell volume can be calculated through multiplying the PBV and the patients Hct together. Therefore, the reduction in Hct would reflect the change in red cell volume [8]. As the hemorrhage is continuing, the fluid persist transfusing to sustain the patients circulating volume. The linear formula proposed by Gross was found intimately following logarithmic formula [9]. According to Gross formula [9], total blood loss = PBV $\left(\mathrm{Hct}_{\mathrm{pre}} \otimes \mathrm{Hct}_{\mathrm{post}}\right) / \mathrm{Hct}_{\text {ave, }}$, where $\mathrm{Hct}_{\text {pre }}$ is

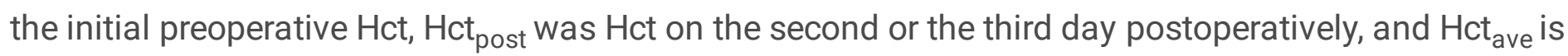
the average of the $\mathrm{Hct}_{\text {pre }}$ and the Hct $\mathrm{post}_{\text {. }}$. Hidden blood loss was calculated by subtracting the visible blood loss from the total blood loss according to the formula of Sehat et al. [10] The formula was

Hidden blood loss $=$ total blood loss $\otimes$ visible blood loss;

When perioperative blood transfusion was performed, Hidden blood loss $=$ total blood loss + allogeneic blood transfusion + autologus blood transfusion $₫$ visible blood loss.

\section{Statistical Analysis}

All date analyses was performed using IBM SPSS 22.0 software. Categorical variables are presented as frequencies and the chi-squared test was took to compare dichotomous variables, normally distributing continuous variables are presented as means \pm SD deviations and independent sample $t$ test was used to compare intergroup difference. The Pearson correlation (used for the normal date), Spearman correlation analysis (used for the non-normal date) and multivariate linear regression analysis were performed to identify risk factors of $\mathrm{HBL}$, including 13 quantitative variables (age, ASA classification, BMI, preoperative Hct, preoperative Cobb angle, prothrombin time, activated partial thromboplatin time, bone mineral density, operation time, segment number, pedicle screw number, autologous blood transfusion, allogeneic blood transfusion, postoperative drainage) and qualitative variables (osteotomy, tranexamic acid and gender). In the qualitative variables, osteotomy and the tranexamic acid were set as " 1 ". Non-osteotomy and non-tranexamic acid were set as " 0 ". The binary logistic regression model was established to identify the the relationship between hidden blood loss and postoperative transfusion. Statistically significant continuous variables were converted to categorical variables through their cut-off points, which was determined by receiver operating characteristic curve (ROC). The level of statistical significance was set at $\mathrm{P}<0.05$. 


\section{Results}

\section{Demographic and clinical characteristics}

A total of 765 patients undergoing posterior spinal fusion corrective surgeries for adolescent idiopathic scoliosis, 128 males and 637 females, were enrolled in the analysis. The mean hidden blood loss was $693.5 \pm 473.4 \mathrm{ml}$, accounting for $53.9 \%$ of the total blood loss. The demographic and clinical characteristics are summarized in Table 1. The mean total blood loss were $1285.7 \pm 437.5 \mathrm{ml}$. The mean change of Hct level was $11.0 \pm 10.9 \%$, and the mean $\mathrm{Hb}$ loss was $36.8 \pm 13.9 \mathrm{~g} / \mathrm{L}$. Approximately 690 $(90.2 \%)$ of patients required intraoperative blood transfusions, and the mean transfusion volume was $672.4 \pm 657.1 \mathrm{ml}$. A total of $205(26.8 \%)$ patients required transfusions of suspended red blood cells after the operation, and the mean transfusion volume was $126.5 \pm 242.9 \mathrm{ml}$.

Table 1 Information of demographic characteristics

\begin{tabular}{|ll|}
\hline Parameters & Statistic \\
\hline Total patients & 765 \\
\hline Gender(M/F) & $128 / 637$ \\
\hline Age & $14.5 \pm 1.7$ \\
\hline Weight, kg & $47.9 \pm 7.9$ \\
\hline Height, cm & $161.2 \pm 8.0$ \\
\hline Total blood loss, ml & $1285.7 \pm 437.5$ \\
\hline Intraoperative blood loss, ml & $926.8 \pm 521.1$ \\
\hline Hidden blood loss, ml & $693.5 \pm 473.4$ \\
\hline Postoperative drainage, ml & $464.2 \pm 200.2$ \\
\hline Change of Hct(\%) & $11.0 \pm 10.9$ \\
\hline Intraoperative transfusion volume, $\mathrm{ml}$ & $672.4 \pm 657.1$ \\
\hline Postoperative transfusion volume, $\mathrm{ml}$ & $126.5 \pm 242.9$ \\
\hline Change of Hb, g/L & $36.8 \pm 13.9$ \\
\hline Mean operation time, min & $250.1 \pm 60.5$ \\
\hline Mean BMl, kg/m2 & $18.4 \pm 2.8$ \\
\hline
\end{tabular}


The Pearson or Spearman correlation analysis for hidden blood loss shown the following parameters with a $p<0.05$ (table 2): gender $(p=0.000)$, operation time $(p=0.002)$, preoperative Hct $(p=0.000)$, preoperative Cobb angle $(p=0.024)$, tranexamic acid $(p=0.000)$, allogeneic blood transfusion $(p=0.000)$ and segment number $(p=0.040)$. To further explore the association between HBL and the risk factors mentioned above, we performed multivariate linear regression analysis. The results proposed that preoperative Hct $(p=0.003)$ and allogeneic blood transfusion $(p<0.0001)$ were independent risk factors for $\mathrm{HBL}$, while tranexamic acid $(p=0.003)$ was negatively related to $\mathrm{HBL}$ (table 3$)$.

Table 2 Results of the Pearson or Spearman correlation analysis for hidden blood loss

\begin{tabular}{|lll|}
\hline Parameters & Sig (2-tailed) & $P$ \\
\hline Age & 0.102 & 0.058 \\
\hline Gender & 0.137 & 0.000 \\
\hline BMI & -0.006 & 0.873 \\
\hline ASA & 0.021 & 0.567 \\
\hline Preoperative Cobb angle & 0.082 & $\mathbf{0 . 0 2 4}$ \\
\hline Preoperative Hct & 0.145 & $\mathbf{0 . 0 0 0}$ \\
\hline Preoperative APTT & 0.049 & 0.176 \\
\hline Preoperative PT & -0.005 & 0.901 \\
\hline Operation time & 0.112 & $\mathbf{0 . 0 0 2}$ \\
\hline Bone mineral density & -0.066 & 0.068 \\
\hline Segment number & 0.074 & $\mathbf{0 . 0 4 0}$ \\
\hline Pedicle screw number & 0.053 & 0.146 \\
\hline Osteotomy & 0.027 & 0.449 \\
\hline Autologous blood transfusion & 0.009 & 0.803 \\
\hline Allogeneic blood transfusion & 0.194 & $\mathbf{0 . 0 0 0}$ \\
\hline Postoperative drainage & -0.017 & 0.631 \\
\hline Tranexamic acid & -0.159 & $\mathbf{0 . 0 0 0}$ \\
\hline
\end{tabular}

Table 3 Results of multivariate linear regression analysis for hidden blood loss 


\begin{tabular}{|lccccc|}
\hline & \multicolumn{2}{l}{ Unstandardized } & \multicolumn{2}{l|}{ Standardized } & \\
\hline coefficient & $\beta$ & SE & $\beta$ & $t$ & P Value \\
\hline Constant & -66.169 & 255.887 & & -0.259 & 0.796 \\
\hline Gender & 95.745 & 49.444 & 0.075 & 1.936 & 0.053 \\
\hline Preoperative Cobb angle & 0.792 & 1.502 & 0.019 & 0.528 & 0.598 \\
\hline Segment number & -15.017 & 7.815 & -0.078 & -1.922 & 0.055 \\
\hline Operation time & -0.393 & 0.308 & -0.050 & -1.274 & 0.203 \\
\hline Tranexamic acid & -126.394 & 41.730 & -0.103 & -3.029 & 0.003 \\
\hline Preoperative Hct & 18.205 & 6.114 & 0.116 & 2.978 & 0.003 \\
\hline Allogeneic blood transfusion & 0.256 & 0.027 & 0.388 & 9.307 & 0.000 \\
\hline
\end{tabular}

\section{HBL was independent risk factor for postoperative transfusion in scoliosis corrective surgery}

As illustrated in table 4, univariate analysis showed that variables including gender, BMI, preoperative $\mathrm{Hb}$, segment number, Pedicle screw number, HBL and postoperative drainage had statistical differences between postoperative transfusion and postoperative non-transfusion group. Statistically significant continuous variables were transformed into categorical variables by their cut-off points. These variables were further analyzed by binary logistic regression and results revealed that $\mathrm{HBL}>850 \mathrm{ml}(\mathrm{P}<0.001, \mathrm{OR}$ : 8.845, 95\% Cl: 5.806-13.290) was the independent risk factor for postoperative blood transfusion (table $5)$.

Table 4 Univariate analysis between postoperative transfusion group and non-transfusion group in scoliosis corrective surgery 


\begin{tabular}{|c|c|c|c|}
\hline Parameters & Transfusion group & Non-Transfusion group & $\mathrm{P}$ \\
\hline Age & $14.3 \pm 1.8$ & $14.5 \pm 1.7$ & 0.504 \\
\hline Gender,male/total(\%) & $17 / 205(8.3 \%)$ & $111 / 560(19.8 \%)$ & 0.000 \\
\hline $\mathrm{BMI}, \mathrm{kg} / \mathrm{m} 2$ & $18.0 \pm 3.3$ & $18.6 \pm 3.0$ & 0.018 \\
\hline Preoperative $\mathrm{Hb}, \mathrm{g} / \mathrm{L}$ & $130.3 \pm 11.5$ & $136.8 \pm 11.2$ & 0.000 \\
\hline Preoperative Cobb angle, degree & $48.9 \pm 12.6$ & $47.2 \pm 10.6$ & 0.055 \\
\hline Preoperative Hct(\%) & $38.7 \pm 3.0$ & $40.3 \pm 2.9$ & 0.949 \\
\hline Preoperative PLT, $10^{9} / \mathrm{I}$ & $228.7 \pm 52.7$ & $232.4 \pm 48.1$ & 0.364 \\
\hline Preoperative INR & $1.06 \pm 0.07$ & $1.05 \pm 0.08$ & 0.151 \\
\hline Preoperative PT, s & $12.1 \pm 0.9$ & $12.0 \pm 0.9$ & 0.061 \\
\hline Preoperative APTT, s & $32.4 \pm 4.0$ & $30.9 \pm 4.0$ & 0.983 \\
\hline Preoperative BUN, mmol/L & $4.4 \pm 1.1$ & $4.4 \pm 1.1$ & 0.593 \\
\hline Preoperative SCR, $\mu \mathrm{mol} / \mathrm{L}$ & $47.2 \pm 9.5$ & $49.5 \pm 10.0$ & 0.536 \\
\hline ASA $(\nabla / \otimes)$ & $94 / 111$ & $296 / 264$ & 0.087 \\
\hline Segment number, $\mathrm{n}$ & $10.7 \pm 2.3$ & $9.9 \pm 2.5$ & 0.028 \\
\hline Operation time, $\min$ & $256.0 \pm 63.3$ & $247.9 \pm 59.3$ & 0.101 \\
\hline Pedicle screw number, $\mathrm{n}$ & $15.6 \pm 2.3$ & $15.0 \pm 2.7$ & 0.010 \\
\hline Osteotomy, n(\%) & $30(14.6 \%)$ & $72(12.9 \%)$ & 0.549 \\
\hline Postoperative drainage, $\mathrm{ml}$ & $545.3 \pm 225.1$ & $434.5 \pm 181.6$ & 0.009 \\
\hline Tranexamic acid, n(\%) & $22(10.7 \%)$ & $80(14.3 \%)$ & 0.230 \\
\hline Intraoperative blood loss, ml & $997.6 \pm 641.1$ & $900.9 \pm 555.9$ & 0.057 \\
\hline $\mathrm{HBL}, \mathrm{ml}$ & $1005.9 \pm 594.1$ & $579.2 \pm 358.7$ & 0.000 \\
\hline
\end{tabular}

Table 5 Results of binary logistic regression analysis for postoperative transfusion in scoliosis corrective surgery 


\begin{tabular}{|lcclcc|}
\hline Variables & $\beta$ & SE & P & OR & $95 \% \mathrm{Cl}$ \\
\hline Gender & 1.347 & 0.319 & $\mathbf{0 . 0 2 1}$ & 3.845 & $2.056-7.192$ \\
\hline Segment number $>11$ & 0.569 & 0.221 & $\mathbf{0 . 0 1 0}$ & 1.766 & $1.145-2.724$ \\
\hline $\mathrm{BMl}>16.7 \mathrm{~kg} / \mathrm{m} 2$ & -0.241 & 0.215 & 0.262 & 0.786 & $0.516-1.198$ \\
\hline Preoperative $\mathrm{Hb}>128 \mathrm{~g} / \mathrm{L}$ & -1.065 & 0.213 & $<0.001$ & 0.345 & $0.227-0.523$ \\
\hline Pedicle screw number $>14$ & -0.189 & 0.243 & 0.436 & 0.828 & $0.514-1.333$ \\
\hline Postoperative drainage $>425 \mathrm{ml}$ & 0.978 & 0.211 & $<0.001$ & 2.658 & $1.759-4.017$ \\
\hline HBL $>850 \mathrm{ml}$ & 2.180 & 0.208 & $<0.001$ & 8.845 & $5.806-13.290$ \\
\hline
\end{tabular}

\section{Discussion}

Posterior spinal fusion corrective surgeries for adolescent idiopathic scoliosis are often associated with significant intraoperative blood loss [11-13]. The amount of visible blood loss can be easily measured in perioperative period, which arouses the attention of clinician and intraoperative hidden blood loss causing by hemolysis as well as oozing into tissue spaces is easily underestimated. Xu et al. [3] reported that the average HBL after posterior lumbar interbody fusion surgery on lumbar spinal stenosis was 423 $\mathrm{ml}$, accounting for $61 \%$ of total blood loss, together with a percentage of $47 \%$ in the total blood loss in the study of Derong et al [14], which was beyond our expectations. Our study showed that the mean HBL for scoliosis surgery was $693.5 \mathrm{ml}$, accounting for $53.9 \%$ of the total blood loss. These results indicated that HBL occupied a considerable proportion in the perioperative blood loss, therefore surgeons and anesthesiologists should pay more attention to physiologic derangement HBL related to.

The concept of HBL was first put forward in 2004 by Sehat et al. [2], however, the underlying mechanism for HBL has not been well clarified. It has reported that the HBL was mainly because of extravasation of the blood into the surgical-site surrounding tissue, blood hemolysis and continuous blood loss after operation. Research has shown that the main reason for HBL was the extravasation of the blood into the tissues through using labeled red blood cells [15-17]. In our study, extensive surgical area for scoliosis surgery provide a wide storage space for bleeding, which consequently, leading to more hidden blood loss compared with transforaminal lumbar interbody fusion surgery $[18,19]$. Therefore, it need to be more rigorous in the paravertebral tissue incisions and wound sutures in scoliosis corrective surgery for physicians. Pattison et al. [20] showed that hemolysis was another possible cause for HBL. Faris et al. [21] reported that the employ of unwashed, filtered and reinfused blood increase hemolysis. Furthermore, in this study, intraoperative allogeneic blood transfusion was an independent risk factor for HBL in multiple linear regression analysis. Thereby we speculated that hemolysis of erythrocyte induced by allogeneic blood transfusion might be, at least in part, responsible for HBL in posterior spinal fusion surgeries. Further prospective studies are needed to elucidate the underlying mechanism of HBL. 
In this study, we investigated and examined the potential risk factors for $\mathrm{HBL}$ involved scoliosis corrective surgery by multivariate linear regression analysis. The results showed preoperative Hct was another independent risk factor for HBL. That is, patients with higher preoperative Hct seem to be in a state of hemoconcentration. More red blood cells would be lost during intraoperative bleeding, which resulted lower Hct when combined with infusion dilution. We speculated that this may be one of the reasons for the more HBL. Our study found that the use of tranexamic acid was negatively related to HBL. Tranexamic acid is a kind of synthetic lysine analog, which was often used in orthopedic surgery as an antifibrinolytic drug. Previous studies have shown that tranexamic acid can effectively reduce the total amount of intraoperative bleeding and the need for blood transfusion in scoliosis corrective surgery [22, 23], but there are few reports on whether tranexamic acid can reduce the HBL involved scoliosis corrective surgery. In transforaminal thoracic interbody fusion, Wang et al. found the application of tranexamic acid significantly reduced HBL [24]. They recommended that tranexamic acid was used as a standard drug to reduce $\mathrm{HBL}$ during perioperative period. In current study, tranexamic acid was used at a loading dose of 1 $\mathrm{g}$ before skin incision, HBL was significantly reduced compared to the control group in posterior spinal fusion surgery. Therefore, intraoperative use of tranexamic acid may contribute to reducing HBL in scoliosis corrective surgery. However, the sample size of these studies was relatively small, the effect of tranexamic acid on HBL including drug dosage still needs to be confirmed in more rigorous prospective studies with a large sample size.

Excessive blood loss can lead to relevant postoperative complications [25], especially for minors, because their compensatory ability is less sound than that of adults. Wen et al believed a positive association between $\mathrm{HBL}$ and operative complications although postoperative complications was not an independent risk factor of HBL [16]. The amount of HBL should be of sufficient concern to clinicians. In this research, the incidence of postoperative blood transfusion was as high as $26.8 \%$. Compared with intraoperative blood transfusion, postoperative anemia is not easily detected in time. Therefore, we explored whether the amount of HBL was related to postoperative transfusion. The binary logistic regression showed that HBL was the independent risk factors for postoperative transfusion for scoliosis corrective surgery. As a result, patients with HBL greater than $850 \mathrm{ml}$, especially those with anemia, should be closely monitored postoperatively in case of potential complications.

There were several limitations in this study. since this study is a descriptive study, it would be apt to cause bias. In the future, the further prospective studies are still needed to confirm the risk factors for HBL in scoliosis corrective surgery. In addition, the Hct was measured twice before surgery in some patients and the latest one was extracted to calculated HBL. Whether the latest measurements reflect preoperative Hct levels is still controversial. Finally, we could not rule out the effect of racial differences on HBL because most patients included in this study were native residents.

\section{Conclusions}

In conclusion, a large amount of HBL was incurred in adolescent idiopathic scoliosis patients undergoing posterior spinal fusion surgeries, which is much more than what we expected formerly in posterior spinal 
fusion surgeries. Allogeneic blood transfusion and preoperative Hct were independent risk factors for $\mathrm{HBL}$, while tranexamic acid was negatively related to $\mathrm{HBL}$. $\mathrm{HBL}$ and its influential factors should be taken into account when considering the perioperative transfusion management in scoliosis corrective surgery. In addition, HBL greater than $850 \mathrm{ml}$ was independent risk for postoperative transfusion in scoliosis corrective surgery. Physicians should pay more attention to these patients with hidden blood loss greater than $850 \mathrm{ml}$ in case of postoperative anemia.

\section{Abbreviations}

HBL: Hidden blood loss; Hct: Hematocrit; Hb: Hemoglobin; BMl: Body mass index; ASA: American society of Anesthesiologists; PLT: platelet; INR: International Normalized Ratio; APTT: Activated partial thromboplastin time; PT: Prothrombin time; BUN: blood urea nitrogen; SCR: serum creatinine

\section{Declarations}

Acknowledgements

None

Authors' contributions

LPW participated in the design of the study, wrote the manuscript and performed the study, XXS and MHL collected and analyzed the data. JLL and YQC designed and supervised the entire study. LPW was a major contributor in writing the manuscript. All authors read and approved the final manuscript.

Funding

NO

Availability of data and materials

The datasets generated during and analyzed during the current study are not publicly available due to hospital regulations but are available from the corresponding author on reasonable request.

Ethics approval and consent to participate

No patients' private information is involved. The retrospective study was waived for the ethical approval and informed consent by the ethic committee of Yijishan Hospital of Wannan Medical College. We confirm that all methods were carried out in accordance with relevant guidelines and regulations.

Consent for publication

Not applicable. 
Competing interests

The authors declare that they have no competing interests from a commercial party related directly or indirectly to the subject of this article.

\section{Author details}

${ }^{1}$ Department of Anaesthesia, Yijishan Hospital of Wannan Medical College, No. 2, Zheshan West Road, Wuhu, Anhui, China. ${ }^{2}$ Department of Orthopedics, Affiliated Taikang Xianlin Drum Tower Hospital, Medical school of Nanjing University, Nanjing, Jiangsu, China. ${ }^{3}$ Department of Anaesthesia, The First Affiliated Hospital of Nanchang University, Nanchang, Jiangxi, China.

\section{References}

1. Elgafy H, Bransford RJ, McGuire RA, Dettori JR, Fischer D: Blood loss in major spine surgery: are there effective measures to decrease massive hemorrhage in major spine fusion surgery? Spine (Phila Pa 1976) 2010, 35(9 Suppl):S47-56.

2. Sehat KR, Evans R, Newman JH: How much blood is really lost in total knee arthroplasty? Correct blood loss management should take hidden loss into account. Knee 2000, 7(3):151-155.

3. Xu S, Liang Y, Wang J, Yu G, Guo C, Zhu Z, Liu H: Blood Loss of Posterior Lumbar Interbody Fusion on Lumbar Stenosis in Patients With Rheumatoid Arthritis: A Case-Control Study. Spine (Phila Pa 1976) 2019, 44(17):E1045-E1052.

4. Xu K, Anwaier D, He R, Zhang X, Qin S, Wang G, Duan X, Tong D, Ji F: Hidden blood loss after hip hemiarthroplasty using the superPATH approach: A retrospective study. Injury 2019, 50(12):22822286.

5. Soliman HAG, Beausejour M, Joncas J, Roy-Beaudry M, Barchi S, Mac-Thiong JM, Labelle H, Grimard G, Parent S: Predicting lowest hemoglobin level and risk of blood transfusion in spinal fusion surgery for adolescent idiopathic scoliosis. Eur Spine J 2019, 28(6):1342-1348.

6. Smorgick Y, Baker KC, Bachison CC, Herkowitz HN, Montgomery DM, Fischgrund JS: Hidden blood loss during posterior spine fusion surgery. Spine J 2013, 13(8):877-881.

7. Nadler SB, Hidalgo JH, Bloch T: Prediction of blood volume in normal human adults. Surgery 1962 , 51(2):224-232.

8. Bourke DL, Smith TC: Estimating allowable hemodilution. Anesthesiology 1974, 41(6):609-612.

9. Gross JB: Estimating allowable blood loss: corrected for dilution. Anesthesiology 1983, 58(3):277280.

10. Sehat KR, Evans RL, Newman JH: Hidden blood loss following hip and knee arthroplasty. Correct management of blood loss should take hidden loss into account. J Bone Joint Surg Br 2004, 86(4):561-565. 
11. Koerner JD, Patel A, Zhao C, Schoenberg C, Mishra A, Vives MJ, Sabharwal S: Blood loss during posterior spinal fusion for adolescent idiopathic scoliosis. Spine (Phila Pa 1976) 2014, 39(18):14791487.

12. Yoshihara $\mathrm{H}$, Yoneoka D: Predictors of allogeneic blood transfusion in spinal fusion for pediatric patients with idiopathic scoliosis in the United States, 2004-2009. Spine (Phila Pa 1976) 2014, 39(22):1860-1867.

13. Ialenti MN, Lonner BS, Verma K, Dean L, Valdevit A, Errico T: Predicting operative blood loss during spinal fusion for adolescent idiopathic scoliosis. J Pediatr Orthop 2013, 33(4):372-376.

14. Xu D, Ren Z, Chen X, Zhuang Q, Hui S, Sheng L, Li S: The further exploration of hidden blood loss in posterior lumbar fusion surgery. Orthop Traumatol Surg Res 2017, 103(4):527-530.

15. Ren Z, Li S, Sheng L, Zhuang Q, Li Z, Xu D, Chen X, Jiang P, Zhang X: Efficacy and Safety of Topical Use of Tranexamic Acid in Reducing Blood Loss During Primary Lumbar Spinal Surgery: A Retrospective Case Control Study. Spine (Phila Pa 1976) 2017, 42(23):1779-1784.

16. Wen L, Jin D, Xie W, Li Y, Chen W, Ding J, Xu J, Ren D: Hidden Blood Loss in Posterior Lumbar Fusion Surgery: An Analysis of Risk Factors. Clin Spine Surg 2018, 31(4):180-184.

17. Nagabhushan RM, Shetty AP, Dumpa SR, Subramanian B, Kanna RM, Shanmuganathan R: Effectiveness and Safety of Batroxobin, Tranexamic Acid and a Combination in Reduction of Blood Loss in Lumbar Spinal Fusion Surgery. Spine (Phila Pa 1976) 2018, 43(5):E267-E273.

18. Yang Y, Zhang L, Liu B, Pang M, Xie P, Chen Z, Wu W, Feng F, Rong L: Hidden and overall haemorrhage following minimally invasive and open transforaminal lumbar interbody fusion. $J$ Orthop Traumatol 2017, 18(4):395-400.

19. Zhang H, Chen ZX, Sun ZM, Jiang C, Ni WF, Lin Y, Wu YS: Comparison of the Total and Hidden Blood Loss in Patients Undergoing Open and Minimally Invasive Transforaminal Lumbar Interbody Fusion. World Neurosurg 2017, 107:739-743.

20. Pattison E, Protheroe K, Pringle RM, et al. Reduction in haemoglobin after knee joint surgery. Ann Rheum Dis 1973;32:582-584.

21. Faris PM, Ritter MA, Keating EM, et al. Unwashed filtered shed blood collected after knee and hip arthroplasties. A source of autologous red blood cells. J Bone Joint Surg Am 1991; 73(8):1169-1178.

22. Yuan QM, Zhao ZH, Xu BS: Efficacy and safety of tranexamic acid in reducing blood loss in scoliosis surgery: a systematic review and meta-analysis. Eur Spine J 2017, 26(1):131-139.

23. Yagi M, Hasegawa J, Nagoshi N, lizuka S, Kaneko S, Fukuda K, Takemitsu M, Shioda M, Machida M: Does the intraoperative tranexamic acid decrease operative blood loss during posterior spinal fusion for treatment of adolescent idiopathic scoliosis? Spine (Phila Pa 1976) 2012, 37(21):E1336-1342.

24. Wentao W, Duan K, Minjie M, Jiang Y: Tranexamic Acid Decreases Visible and Hidden Blood Loss Without Affecting Prethrombotic State Molecular Markers in Transforaminal Thoracic Interbody Fusion for Treatment of Thoracolumbar Fracture-Dislocation. Spine (Phila Pa 1976) 2018, 43(13): E734-E739. 
25. Huang YH, Ou CY: Significant Blood Loss in Lumbar Fusion Surgery for Degenerative Spine. World Neurosurg 2015, 84(3):780-785. 